\title{
CONNECT TO LEARNING
}

\author{
USING E-PORTFOLIOS IN HYBRID PROFESSIONAL \\ DEVELOPMENT
}

\author{
Bret Eynon, Judit Török \\ LaGuardia Community College \\ Laura M. Gambino \\ New Community College
}

Based at LaGuardia Community College, the Connect to Learning (C2L)
project has developed an innovative hybrid professional development
model using e-portfolios, online conversations, and face-to-face meetings
to support campus leadership teams as they strengthen e-portfolio
initiatives on twenty-five diverse campuses nationwide. The C2L model
adapts a conceptual framework of inquiry, reflection, and integration to a

We thank the U.S. Department of Education Fund for Improvement of PostSecondary Education for its support of the $\mathrm{C} 2 \mathrm{~L}$ project and are grateful to the participating faculty, staff, and institutions of the $\mathrm{C} 2 \mathrm{~L}$ community for their dedication to innovation and collaboration. Our thanks also to those whose insightful comments on drafts helped us clarify our thinking, including Randy Bass, Trent Batson, Alison Carson, Helen Chen, Peter Felten, Pat Hutchings, Mary Huber, Terry Rhodes, and Howard Wach. 
hybrid context and addresses the challenge of local professional development leadership for classroom and institutional change.

E-portfolios have emerged as an innovative feature of today's higher education landscape. The promise of enhanced student learning and authentic assessment has made e-portfolios broadly attractive. Data show that the number of colleges offering e-portfolio services tripled from 2003 to 2010 (Green, 2011). Using e-portfolios effectively can be challenging, however. Many colleges approach e-portfolios only as a technology and fail to grasp that the value depends on sophisticated pedagogy and institutional practice.

The Connect to Learning project $(\mathrm{C} 2 \mathrm{~L})$, funded by the Fund for the Improvement of Secondary Education (FIPSE), assembles a diverse national network to address these challenges, linking e-portfolio leadership teams from twenty-five campuses to build a community of practice and develop a national resource site for e-portfolio initiatives. Launched in 2011, C2L is spearheaded by LaGuardia Community College, City University of New York (CUNY), working with the Association for Authentic, Experiential and Evidence Based Learning, an international e-portfolio organization, and twenty-four partner campuses from across the United States.

To do national professional development with limited resources, C2L employs a hybrid structure, linking online seminars and face-to-face meetings with campus experimentation. Campus e-portfolios created by each team unify the hybrid process. Three design principles-inquiry, reflection, and integration-inform our professional development process. Preliminary evidence suggests that this approach is helping C2L campus teams strengthen their work with hundreds of faculty, deepening e-portfolio practice that serves tens of thousands of students, and builds engagement in key integrative learning processes.

\section{The C2L Professional Development Model}

C2L builds on LaGuardia's successful e-portfolio project (Eynon, 2009) and three years of the Making Connections project (2007-2010), a professional development effort to help New York City-area campuses launch e-portfolio initiatives. Holding monthly face-to-face meetings at LaGuardia, Making Connections worked with sixty campuses over three years, helping teams explore issues related to e-portfolio use, including 
integrative learning pedagogy, reflection, professional development techniques, technology, and authentic outcomes assessment.

In 2011, LaGuardia's Making Connections National Resource Center launched a new FIPSE-funded project: Connect to Learning: e-Portfolio, Engagement, and Student Success. This new effort expands to campuses nationwide and focuses on campuses that have e-portfolio initiatives already well under way. The primary goal is to create a community of practice where, guided by a leadership team based at LaGuardia's Making Connections Center, campus teams explore relevant scholarly literature and share their own practices, learning from each other to deepen their e-portfolio work (Sherer, Shea, \& Kristensen, 2003). A secondary goal is to harvest the learning and practices to create a national resource website available to the larger e-portfolio field.

Selected in a competitive application process, the $\mathrm{C} 2 \mathrm{~L}$ campuses range from two-year colleges such as CUNY's Queensborough Community College to private liberal arts colleges such as Manhattanville College and Research I campuses such as the University of Delaware and San Francisco State University. Each campus has an active e-portfolio initiative, addressing campus-specific goals. The leaders of those initiatives-two to four members per campus-take part in $\mathrm{C} 2 \mathrm{~L}$ activities.

To help teams deepen their knowledge of e-portfolio practice, the $\mathrm{C} 2 \mathrm{~L}$ leadership used online tools to design a hybrid professional development model with four components:

o Campus practice. Each team works with students, faculty, and staff on their campus, using e-portfolios to enhance pedagogy and strengthen outcomes assessment. The $\mathrm{C} 2 \mathrm{~L}$ process seeks to surface campus practices and make them more visible, conscious, and intentional. At the same time, $\mathrm{C} 2 \mathrm{~L}$ asks campus teams to experiment with new practices, developing plans and trying out strategies to advance campus initiatives.

- Face-to-face meetings. After an initial face-to-face launch meeting, $\mathrm{C} 2 \mathrm{~L}$ has held annual summer institutes, gathering teams for discussion, exchange, and collaborative work.

o Online forum. The Making Connections website hosts a Moodlebased threaded discussion forum; each year, $\mathrm{C} 2 \mathrm{~L}$ organizes five to six conversations, called "Jams," focusing on specific topics related to e-portfolio practice, such as designing reflective pedagogy for e-portfolio-enhanced courses or e-portfolios for outcomes assessment.

- Campus e-portfolios. While helping campus teams use e-portfolios with their students, C2L also employs e-portfolios in its professional 
development process. Every campus has created a C2L project portfolio that is used to post campus information, practices, plans, and reflections. Examined during the online Jams and the face-toface institutes, the recursive use of the campus e-portfolios serves as a unifying element for the entire process.

The forum and the campus e-portfolios are related but distinct. While Jams are temporal events, the campus portfolios endure, helping campuses make connections across issues and topics. The e-portfolios link the online and face-to-face exchange back to the tasks of scaling up campus e-portfolio initiatives, grounding project-wide conversation in evolving campus practice.

C2L's conceptual framework is grounded in three complementary design principles: inquiry, reflection, and integration. These three principles are applicable to e-portfolio pedagogy and practice on the campuses; at the same time, they inform the $\mathrm{C} 2 \mathrm{~L}$ professional development process. In this sense, we follow Thomas Angelo's (2001) precept: to model in the professional development process the pedagogies we seek to nurture in the classroom.

The concepts of inquiry, reflection, and integration are well developed in the literature. By inquiry, we mean the investigative, problem-based learning described by David Kolb and others-a cyclical process of asking questions about authentic problems, analyzing relevant evidence, creating and presenting evidence-based solutions, reflecting on the learning process, and developing new questions and plans for further inquiry (Dewey, 1938b; Kolb, 1984). At its best, e-portfolio pedagogy engages students in a recursive inquiry into their own learning and their evolving identities as learners and simultaneously supports institutional inquiry into learning through holistic outcomes assessment. Meanwhile, inquiry has a rich history in professional development (Butler \& Schnellert, 2012). Programs with an emphasis on collective inquiry ask faculty and staff to raise questions, explore issues, and use their classrooms as laboratories for scholarly experiments with new pedagogies (Palmisano, 2012). Through sustained collective inquiry, faculty and staff construct new knowledge and understandings.

Reflection can be linked with inquiry but can also stand alone. From a Deweyan perspective, reflection complements experience; the purpose of reflection is to make connections among experiences, deepening continuities and empowering the meaning-making process (Dewey, 1938a; Rodgers 2002a). Reflection is pivotal to meaningful student e-portfolios, which function as sites for prompting, documenting, and sharing 
students' reflection on their learning. In a professional development process, reflective activities help participants learn from their experiences and develop as reflective practitioners (Rodgers, 2002b; Schön, 1983).

Integration, or integrative learning, has gained new visibility in higher education. For students, integrative learning involves making connections and transferring knowledge across courses, disciplines, and semesters, linking academic learning with lived experience into a more intentional whole (Huber \& Hutchings, 2005). Guided by integrative pedagogy, students use e-portfolios to bring together work from multiple contexts, consider the relation between their classrooms and their lives outside class, and construct new identities as learners. In professional development, integration not only engages faculty and staff in the effort to employ integrative strategies with students; it also asks these professionals to transfer their own knowledge and insight from specific instances to broader contexts and applications. C2L sees integration in the process of moving from seminar to classroom, deepening and sustaining innovations, turning creative, one-shot experiments into broadly adopted changes in practice (Hutchings, 2006). For e-portfolio projects, integration demands going beyond individual classrooms to address institutional curricula, structure, and culture-issues that involve campus leaders, budgets, and governance. As Randy Bass (2012) writes, "We must fully grasp that students will learn to integrate deeply and meaningfully only insofar as we design a curriculum that cultivates that; and designing such a curriculum requires that we similarly plan, strategize and execute integratively across the boundaries within our institutions" (p. 32).

Because these three design principles speak to rich and adaptive processes of both student and professional learning, we believe they are broadly applicable in professional development. Moreover, we have found that these design principles amplify the value of e-portfolio use in professional development. The e-portfolio is inherently well suited to support professional inquiry into learning, the deepening of reflective practice, and the connective process central to integration. Used with social pedagogy, e-portfolios enrich collaboration as participants move through recursive cycles of inquiry, reflection, and integration.

\section{The C2L Model in Action}

\section{Campus Activity}

The $\mathrm{C} 2 \mathrm{~L}$ process is grounded in the experience of campus teams working in diverse settings. Each team works to advance the use of e-portfolios on 
its campus, addressing campus-specific goals and conditions. Some campus teams have been active for a decade; others are two to three years old. Most teams lead campus professional development, using a range of approaches to address self-selected topics that may include reflection, integrative pedagogy, and holistic outcomes assessment. A set of snapshots suggests the work of campus teams:

o Three Rivers Community College (TRCC) in southeast Connecticut launched its e-portfolio project in 2004, focused on career portfolios for nursing students. The nursing faculty who lead the project explain that in 2006, their focus "shifted from technology to pedagogy." Adding courses each semester, they integrated e-portfolios program-wide. Students were introduced to program outcomes when they began their portfolios. Particular attention was given to reflection; the goal is for "students to reflect on action and develop reflective in action abilities." E-portfolios have served TRCC well in nursing professional accreditation, and its team has opened a conversation with the TRCC general education committee about using e-portfolios for broader outcomes assessment.

- Manhattanville College, a liberal arts college in New York's Hudson Valley, began exploring e-portfolios in 2009 to reinvigorate the long-standing use of paper portfolios. The team seeks to "develop skills of reflection, self-assessment and integrative thought, utilizing e-portfolio." Aiming to build a systemic initiative, the team has used teaching and learning circles to nurture pockets of sophisticated e-portfolio use, such as the first-year seminar, the Center for Career Development, and a doctoral program in educational leadership. Recognizing the value of "the voice of students who have worked with e-portfolio in their classes," Manhattanville uses student "e-terns" to help faculty and peers. A growing number of majors have expressed interest in using e-portfolio to do "authentic and holistic outcomes assessment, designed to improve student learning."

o Salt Lake Community College (SLCC), a multicampus Utah college, serves sixty thousand credit and noncredit students per year. In 2009, faculty approved a requirement that students use an e-portfolio in all general education courses. Since then, over thirty-five thousand student e-portfolios have been created. The SLCC team focuses on three main goals: "promoting engagement and intentionality among our students, adding coherence to our General Education program, and assessment of General Education." Encouraging sophisticated 
e-portfolio pedagogy needs ongoing attention, but the SLCC initiative has grown in unexpected ways. E-portfolios have been woven into developmental math and technical education programs and have become an integral part of how students document servicelearning experiences. A handful of faculty now use e-portfolios to create tenure portfolios.

o Boston University (BU) began using e-portfolios in 2008 in its College of General Studies, a two-year core curriculum program enrolling eleven hundred students each year; it is now a requirement, supporting assessment and helping students "make connections among their classes, reflect on their learning, enhance their academic projects with videos and other images, and archive their writings and extra-curricular activities." In 2011, BU assessed a large set of student e-portfolios, gathering quantitative and qualitative data on patterns of student progress. Pleased with their assessment work and the use of e-portfolios "to facilitate student-centered learning," the team acknowledges the challenge of sustaining faculty and student support. Looking ahead, they'll focus on engaging students through a peer mentor program and a student e-portfolio showcase.

Campus work is the site for professional learning; implementation is part of the inquiry process, a chance to test theory in the diverse campus contexts. Those campus contexts present challenges as well as opportunities. Campus teams confront not only tight budgets and resistance to change, but also the complexity of e-portfolio as an educational innovation. The most dynamic e-portfolio initiatives balance sophisticated pedagogy, digital technology, and holistic outcomes assessment. E-portfolio learning spans disciplines and semesters, linking academic and cocurricular learning, cognition, and affective development. Integrative e-portfolio practice asks faculty to step outside the comfort zone of individual courses and disciplinary training. Developing a meaningful e-portfolio initiative requires sustained cross-campus collaboration and systemic thinking by campus stakeholders. To deepen and scale e-portfolio initiatives, C2L's campus teams must recursively engage students, faculty, staff, and campus leaders, helping them focus on holistic student learning and its implications for campus structure and culturewhat John Tagg (2000) called "double-loop" learning. Recognizing the importance of this task, $\mathrm{C} 2 \mathrm{~L}$ seeks to help campus teams build not only understanding of e-portfolio pedagogy and practice but also skills as educational change agents, working to promote a campuswide culture of learning (Butler \& Schnellert, 2012). 
Face-to-Face Meetings

To help campus teams develop and test effective strategies for this campus work, C2L asks them to engage in a sustained process of collective inquiry and exchange, examining the literature, their own practices, and others' practices. Reflecting on this inquiry, the process asks them to take what they learn and integrate it back into their own campus activities.

Shared inquiry and exchange takes place face-to-face and online. Four face-to-face meetings were included in the project's three-year time line. In January 2011 we held a face-to-face kick-off meeting that brought together our new community, building trust among a diverse group of campuses, and introducing our hybrid structure. We have now held two summer institutes, bringing teams together for practice sharing, discussions of shared challenges, and development of strategies for evaluating the impact of e-portfolio activity.

Prior to the meetings, teams use their campus e-portfolios to post campus plans and goals for the upcoming year and review each other's plans. During the institute, teams build on this exchange, meeting with other teams to provide feedback; they then return to their own plans, using insights from the exchange to advance their campus initiatives more effectively. Team planning time and cross-campus community building are built into each institute. After each institute, teams use their campus e-portfolios to post reflections on their learning as well as revised campus plans.

\section{Online Forum}

Recognizing that annual meetings are not sufficient to support its community of practice, $\mathrm{C} 2 \mathrm{~L}$ uses a Moodle-based forum for online conversation, collaboration, and collective inquiry. In the forum, C2L hosts threaded asynchronous discussions-the Jams. It holds five to six timelimited Jams per year, each running seven to ten days, focusing on a specific theme such as reflective pedagogy (see table 7.1).

Most Jams involve a review of relevant literature, multimedia presentations, small group discussion, sharing campus practices, and team reflection. They often begin with readings of key texts from the relevant literature. For example, in a fall $2011 \mathrm{Jam}$ that explored linkages between e-portfolios and high-impact practices (particularly capstone and firstyear experience programs), teams read articles from Peer Review (Carey, 2006) focused on the first college year; selections from Gardner and Van der Veer's (1998) The Senior Year Experience: Facilitating Integration, Reflection, Closure, and Transition; and a piece by George Kuh (2008). 
Table 7.1 Jam Topics and Dates, 2011 and 2012

\begin{tabular}{|c|c|}
\hline Dates & Topic \\
\hline $2 / 25-3 / 7 / 2011$ & Reflective Pedagogy for e-Portfolio Classrooms \\
\hline $4 / 7-4 / 18 / 2011$ & Best Practices in Integrative Faculty Development \\
\hline $6 / 1-6 / 9 / 2011$ & $\begin{array}{l}\text { Goals and Plans: Building Your 2011-12 e-Portfolio } \\
\text { Initiative }\end{array}$ \\
\hline 9/19-9/29/2011 & $\begin{array}{l}\text { From Beginning to End: Integrative e-Portfolios in First } \\
\text { Year Experience and Capstone Courses }\end{array}$ \\
\hline $11 / 1-11 / 11 / 2011$ & $\begin{array}{l}\text { Strengthening our Evaluation Practices: Sharing Revised } \\
\text { Plans, Getting Assistance }\end{array}$ \\
\hline $1 / 17-1 / 25 / 2012$ & $\begin{array}{l}\text { E-Portfolio and Social Pedagogy: A Conversation with } \\
\text { Randy Bass }\end{array}$ \\
\hline $2 / 27-3 / 7 / 2012$ & $\begin{array}{l}\text { C2L's National Development Model of e-Portfolio Practice: } \\
\text { A Structured Resource for the Field }\end{array}$ \\
\hline $4 / 16-4 / 30 / 2012$ & $\begin{array}{l}\text { Polishing Our Reflective e-Portfolio Practices: Deepening } \\
\text { Our Work, Preparing to Go Public }\end{array}$ \\
\hline $6 / 4-6 / 12 / 2012$ & $\begin{array}{l}\text { Becoming a Learning College: E-Portfolios for Outcomes } \\
\text { Assessment }\end{array}$ \\
\hline $9 / 27-10 / 5 / 2012$ & $\begin{array}{l}\text { Scaling Up: Strategies for Institution-Wide e-Portfolio } \\
\text { Integration }\end{array}$ \\
\hline $1 / 12-11 / 20 / 2012$ & Professional Development Polished Practices \\
\hline
\end{tabular}

Virginia Tech and LaGuardia shared multimedia presentations on their first-year and capstone e-portfolio programs. After watching these presentations on their own time, teams used the forum to discuss the presentations and readings and consider implications for their own work. Engagement in the Jams has been high; in this Jam, for example, participants posted more than two hundred comments.

\section{Campus e-Portfolios}

Using the Digication platform, each campus team has created its own C2L e-portfolio, customizing it with images and information about its campus, its project, and its leadership team. Teams construct their portfolios recursively, regularly adding plans, reports, evaluation evidence, practice descriptions, and reflections. Rich with detail, evidence, and reflection, the campus e-portfolios support the inquiry processes taking place faceto-face and online, building integrative connections with ongoing campus practice.

Teams use their e-portfolios to document campus practice, preparing detailed descriptions of integrative and reflective activities and attaching 
samples of faculty and student work, including assignments, grading rubrics, and student portfolios. The inclusion of student work (shared by permission) grounds the descriptions in real artifacts of student learning. Descriptions include reflections on strengths and challenges. $\mathrm{C} 2 \mathrm{~L}$ teams have a wealth of knowledge and experience; developing their e-portfolios prompts them to articulate their insights, making tacit knowledge more explicit and accessible.

In $\mathrm{C} 2 \mathrm{~L}$, e-portfolios are more than static repositories. We ask teams to share their e-portfolios, making them sites for interactive social learning. The e-portfolios are often used in Jams, alongside the forum. Building on questions raised in the forum, teams deepen their inquiry by sharing examples of relevant e-portfolio practice. They work in small groups, using the e-portfolios to read each other's practices. They use Digication's commenting feature to ask questions and provide detailed, grounded observations. This process not only provides access to concrete examples of practice; it also supports peer critiquing. Initial practice descriptions are seen as drafts; after engaging in discussion, teams rethink, refine, and polish their write-ups.

As the last step in each Jam, teams post written reflections to their e-portfolio. We ask participants to think about what they learned from each part of the Jam: the readings, forum, shared practices, and comments. This reflective process prompts participants to articulate their own learning and growth, become more reflective practitioners, and translate this learning to their own campus activity.

Campus e-portfolios document not only classroom practices but also the team's broader work: the intentional process of strategically building an e-portfolio project. C2L asks teams to engage in a yearly cycle of developing campus plans and evaluation reports and posting them in their e-portfolios. Developing a campus plan requires careful reflection; teams examine their campus work from many angles, thinking about ways they might integrate knowledge acquired from the $\mathrm{C} 2 \mathrm{~L}$ process into their project. In annual reports, teams summarize accomplishments and provide evaluation data. The evaluations ground inquiry with evidence, encouraging a more structured action research process; this process gains depth by combining inquiry at multiple levels of granularity, from individual practice to institutional structure and culture. Shared in e-portfolios, plans are reviewed by other teams and discussed at institutes. This advances the cycle of inquiry, reflection, and integration across multiple levels of collaboration; campus e-portfolios help unify a multilayered community of practice focused on learning. 
Campus e-portfolios thus serve an integrative function, linking other elements of the $\mathrm{C} 2 \mathrm{~L}$ model. Useful in and of themselves, they are most valuable in the ways they connect campus practices to institutes and the forum. When teams share practices during the Jams, they contribute to the project's multilayered collective inquiry. At the same time, the e-portfolios facilitate the process of reflection and integration, helping teams bring their learning back from the community exchange and apply it to the advancement of local initiatives.

\section{Preliminary Findings}

As C2L begins its third year, preliminary evidence suggests that it is advancing toward its goals. Participant surveys, student outcomes data, and campus activity reports suggest that the process supports professional learning about e-portfolio pedagogy and practice and helps teams to build their campus initiatives.

One way to assess the program's value to participants is to ask for feedback. In January 2012, after twelve months of project activity, C2L leaders administered an online evaluation with open-ended and multiple-choice items. Three-quarters of the forty-eight respondents ( 76.1 percent) reported that overall, their participation in C2L had been either "very helpful" or "quite helpful." On another item, 97.8 percent "agreed" or "strongly agreed" that the C2L experience had "deepen[ed] my insights into e-portfolio Pedagogy." Nearly four-fifths (78.2 either) either "agreed" or "strongly agreed" that taking part in C2L had "spurr[ed] our team to focus on planning and evaluation."

Qualitative feedback adds nuances to our understanding of the value of the $\mathrm{C} 2 \mathrm{~L}$ experience. While some comments offered constructive suggestions for making the Jams more efficient and others noted the challenge of taking part in a demanding process while also leading a campus project, most highlighted the value of the process. Following is a selection of responses to the question, "How would you summarize the most interesting thing you learned through $\mathrm{C} 2 \mathrm{~L}$ ?"

"The readings and discussion on social pedagogy deepened and renewed my commitment to the concept and stimulated me to consider more ways to increase collaboration and reflection through e-portfolios as well as other classroom activities."

"Being part of this project has ensured that the e-portfolio 'agenda' has been moving forward on our campus in a focused and timely manner." 
"The wealth of practices around the country. 1 think we innovate well, but I'm always surprised by the ways to use e-portfolios that I hadn't thought of."

"The best part of $\mathrm{C} 2 \mathrm{~L}$ is having the opportunity to share practices and exchange ideas with other campus teams. This opportunity provides new ideas to bring back and work with on our own campus."

Feedback suggests that the combination of face-to-face, online, and campus-based activity in $\mathrm{C} 2 \mathrm{~L}$ is highly meaningful for participants. C2L teams are not only developing new insights into e-portfolio pedagogy and practice but also see the process as directly relevant to their campus work.

Campus reports represent another major data source. These annual reports provide data on the scope of the campus implementations, student learning outcomes, and narrative accounts of $\mathrm{C} 2 \mathrm{~L}$-related activities. They indicate that teams drew on $\mathrm{C} 2 \mathrm{~L}$ processes as they engaged large numbers of faculty in e-portfolio-related professional development and teaching, serving large numbers of students in e-portfolio-intensive courses. In the 2011-12 academic year, over 860 faculty members participated in campus-based C2L-related professional development; over 760 instructors used e-portfolios in 895 course sections linked to C2L, which served over twenty thousand students in 2011-12.

The 2012 reports began to examine the impact of e-portfolio practice on student learning, but the evidence was limited in some respects. Proving a causal connection between professional development and change in student learning is always challenging (Fink, 2013). C2L campus teams have limited staff and budgets; they are not trained as evaluators and can be overwhelmed by the tasks of leading complex projects while also meeting other campus responsibilities. Getting campus institutional research offices to evaluate the impact of e-portfolios can be difficult. Aware of these challenges, C2L has used Jams and institute workshops to help teams plan ways to gather evidence of the impact of e-portfolios on student learning. Most $\mathrm{C} 2 \mathrm{~L}$ teams have begun to collect and analyze evidence, such as student and faculty surveys, retention rates, and GPA data-for example:

o At Tunxis Community College, a year-long comparison between e-portfolio and non-e-portfolio sections of developmental English courses showed a 3 to 5 percent increase in student pass rates and an almost 6 percent increase in retention rates. 
o At Manhattanville College, the average GPA of students participating in an e-portfolio pilot was 3.097, while in a comparable, none-portfolio cohort, the average GPA was 2.771.

o At Indiana University-Purdue University Indianapolis, the one-year fall-to-fall retention rate for students who complete an e-portfolio ( 80 percent) was significantly higher than for students who did not (72 percent).

To complement the examination of student outcomes, C2L developed a network-wide C2L Core Student Survey, piloted in 2011-2012. Responses to e-portfolio-specific questions suggest that nearly two-thirds (64.8 percent) of the 4,137 student respondents felt the e-portfolio experience had been valuable in helping them to deepen their learning and "agreed" or "strongly agreed" with the statement, "Building my e-portfolio helped me to think more deeply about the content of this course." In addition, 63.8 percent "agreed" or "strongly agreed" with, "Building my e-portfolio helped me to make connections between ideas."

E-portfolio-specific questions were flanked by a set of questions about integrative learning used with permission from the National Survey of Student Engagement (NSSE). Since the NSSE and the Community College Survey of Student Engagement (CCSSE) are nationally normed, we could use weighted national means from the NSSE First Year and the CCSSE to do a preliminary comparison. The results suggest that students in C2Lrelated courses were more likely than students nationwide to report engagement in integrative learning. For example, in response to the question, "To what extent has your experience in this course emphasized synthesizing and organizing ideas, information and experiences in new ways," 79.4 percent of C2L-related students responded "quite a bit" or "very much." Nationally the comparable figure (on a weighted average of national NSSE/CCSSE scores) was 64.1 percent. Similarly, on a question about whether their experiences had "emphasized applying theories or concepts to practical problems or in new situations," an indication of knowledge transfer and integration, 74.3 percent of $\mathrm{C} 2 \mathrm{~L}$ students responded "quite a bit" or "very much," compared to a national figure of 63.5 percent. On a question asking whether their experiences had "contributed to your knowledge, skills, and personal development in understanding yourself," indicating a connection between academic learning and identity, the difference was even larger: 78.2 percent of $C 2 L$ students responded "quite a bit" or "very much," compared to a national figure of 58.5 percent. While rough and preliminary, these figures may be evidence 
that C2L's campus teams are using e-portfolios to foster integrative learning. For now, these figures are best understood as an indication of the value of further research.

In campus reports, teams describe what they did in the past year to advance their local e-portfolio implementations. They report on the strategy and focus of their professional development processes and their work with e-portfolios around outcomes assessment. They discuss efforts to work with student groups, departments, administrators, and teaching centers to scale their e-portfolio initiatives and nurture a campuswide learning culture. On each of these issues, campus reports discussed what they did to deepen their work and address issues raised in the Jams.

Does the $\mathrm{C} 2 \mathrm{~L}$ experience shape these practices? The reports provide evidence that the processes of inquiry and reflection advance integration of C2L approaches into campus practice. In their reports, campuses explicitly identified ways that C2L participation had shaped plans and activities. The following excerpts suggest the breadth of the integration process:

Participation in C2L has been essential to the success we have had with our e-portfolio launch at Manhattanville College. Indeed, we could not have rolled out e-portfolio to the entire freshman class this year without the support that $\mathrm{C} 2 \mathrm{~L}$ provides. The Manhattanville team has used C2L activities as a model when working in our Teaching/ Learning Circles (TLCs). In our TLCs, we use many of the readings we've used in C2L, including Lewis and Fournier's "A Catalyst without a Mandate," Carol Rogers' essay on "John Dewey and Reflective Thinking," and "Designing Learning Activities" from AAC\&U's Electronic Portfolios and Student Success. (Manhattanville College)

Though the changes are slow, I believe the one thing that $\mathrm{C} 2 \mathrm{~L}$ is encouraging us to do that we would not do otherwise is to base our activities in real data-to determine what has been effective and what has not and to develop our program based on that data. (Virginia Tech)

The most substantive part of the $\mathrm{C} 2 \mathrm{~L}$ participation for us has been the opportunity to view other colleagues' practices... These concrete examples are extremely valuable to us as teachers as is the feedback we receive on our own practices. (Northwest Connecticut Community College)

The SLCC team has taken quite a few meaningful ideas away from our C2L participation regarding assignments \& reflection, 
project planning, faculty development, assessment, and using social pedagogy in the classroom... Sharing how other campuses use e-portfolios for assessment also helped us ... modify and strengthen our assessment this year. (Salt Lake Community College)

Our participation in C2L has enhanced our understanding of the importance of reflection in the learning process and the key role e-portfolios can play in facilitating students' self-reflections. We have implemented self-reflection assignments at the end of both the freshman and sophomore years now, and we probably would not havedone so, or done so this quickly, without the work of C2L. (Boston University)

These excerpts indicate some of the ways the $\mathrm{C} 2 \mathrm{~L}$ process appears to affect campus e-portfolio initiatives. The deepest impact so far has been on reflective e-portfolio pedagogy. But the effects ripple out from there, shaping faculty development, outcomes assessment, programmatic evaluation, work with stakeholders, linkages with high-impact practices, and other aspects of institutional e-portfolio integration. While not conclusive, this evidence, along with the feedback survey and other data provided by campuses, suggests that C2L's professional development model has already begun to demonstrate its effectiveness.

\section{Implications}

Guided by the design principles of inquiry, reflection, and integration, C2L's hybrid, e-portfolio-based model shows signs of being a meaningful professional development process. Working effectively within this multicampus partnership, the $\mathrm{C} 2 \mathrm{~L}$ model may offer opportunities in other professional development contexts as well. First, the $\mathrm{C} 2 \mathrm{~L}$ hybrid model takes proven face-to-face practices and, using e-portfolio, translates them into an online environment. Second, $\mathrm{C} 2 \mathrm{~L}$ provides a design framework for structuring conversations around teaching practices that can be used with individual faculty, small groups, and larger organizations.

The use of the e-portfolio as a tool and a pedagogy for guiding professional development could be adapted to a wide range of settings and topics. In a hybrid professional development context, it complements threaded discussion, grounding it more firmly in practice. The detailed practice write-ups and campus reports included in the campus e-portfolios give depth and specificity to the professional development conversation. The connection to student work facilitates a focus not only on teaching but also on learning. Used with social pedagogy, e-portfolio-based 
interaction creates a wealth of commentary that is directly attached to practice. This grounded commentary stays with the e-portfolio, easily accessed as participants reflect and revise. In an online or a face-to-face setting, the use of the e-portfolio as a professional learning tool can strengthen continuity and connections between collective discourse and foster a sustained and recursive process of change.

Similarly, the design principles of inquiry, reflection, and integration have application in other professional development settings. The value of inquiry and reflection in professional learning is widely recognized. Adding integration recognizes the importance of integrative learning not only for students but also for professionals and institutions. It transforms the processes of inquiry and reflection, highlighting the importance of connecting individual and episodic innovation to sustained institutional change. In a period when colleges are under great pressure to make largescale changes and improve student learning, professional development models that help educators examine and address the connections between classroom change and institutional transformation may prove to be critical to the future of higher education.

\section{REFERENCES}

Angelo, T. (2001). Doing faculty development as if we value learning most: Transformative guidelines from research and practice. In D. Lieberman \& C. Wehlburg (Eds.), To improve the academy: Resources for faculty, instructional and organizational development, Vol. 19 (pp. 97-112). San Francisco: CA: Jossey-Bass.

Bass, R. (2012). Disrupting ourselves: The problem of learning in higher education. Educause Review Online. Retrieved from http://net.educause.edu/ir/library /pdf/ERM1221.pdf

Butler, D., \& Schnellert, L. (2012). Collaborative inquiry in teacher professional development. Teaching and Teacher Education, 28(8), 1206-1220.

Carey, S. (Ed.). (2006). Peer Review, 8(3).

Dewey, J. (1938a). Experience and education. New York, NY: Macmillan.

Dewey, J. (1938b). Logic: The theory of inquiry. New York, NY: Holt.

Eynon, B. (2009). "It helped me see a new me": e-portfolio, learning and change at LaGuardia Community College. Academic Commons. Retrieved from http://www.academiccommons.org/commons/essay/e-portfolio-learning-and -change

Fink, L. (2013). Innovative ways of assessing faculty development. In C. McKee, M. Johnson, W. Ritchie, \& W. Tew (Eds.), New Directions for Teaching 
and Learning: No. 133. The breadth of current faculty development practitioners' perspectives (pp. 47-59). San Francisco, CA: Jossey-Bass.

Gardner, J., \& Van der Veer, G. (1998). The senior year experience: Facilitating integration, reflection, closure, and transition. San Francisco, CA: Jossey-Bass.

Green, K. (2010). 2010 Campus computing report. Encino, CA: Campus Computing Project.

Huber, M. T., \& Hutchings, P. (2005). Integrative learning: Mapping the terrain. Washington, DC: Association of American Colleges and Universities.

Hutchings, P. (2006). Fostering integrative learning through faculty development. Carnegie Foundation for the Advancement of Teaching. Retrieved from http:// gallery.carnegiefoundation.org/ilp/uploads/facultydevelopment_copy.pdf

Kolb, D. (1984). Experiential learning: Experience as the source of learning and development. Englewood Cliffs, NJ: Prentice Hall.

Kuh, G. (2008). High impact practices: What they are, who has access to them, and why they matter. Leap. Retrieved from http:/www.aacu.org/leap/hip.cfm

Palmisano, M. (2012). Collaborative inquiry differs from traditional professional development. Retrieved from hrtp://www.literacyinlearningexchange.org /collaborative-inquiry-differs

Rodgers, C. (2002a). Defining reflection: Another look at John Dewey and reflective thinking. Teachers College Record, 104(4), 842-866.

Rodgers, C. (2002b). Seeing student learning: Teacher change and the role of reflection. Voices inside schools. Harvard Educational Review, 72(2), 230-253.

Schön, D. (1983). The reflective practitioner: How professionals think in action. New York: Basic Books.

Sherer, P. D., Shea, T. P., \& Kristensen, E. (2003). Online communities of practice: A catalyst for faculty development. Innovative Higher Education, $27,183-194$.

Tagg, J. (2007). Double-loop learning in higher education. Change, 39(4), 36-41. 